\title{
Physical fitness of primary school children in the reflection of different levels of gross motor coordination
}

\author{
Ingrid Ružbarská* \\ Faculty of Education, University of Presov in Presov, Presov, Slovakia
}

Copyright: (C) 2016 I. Ružbarská. This is an open access article licensed under the Creative Commons Attribution License (http://creativecommons.org/licenses/by/4.0/).

\begin{abstract}
Background: Lower level of motor competences may result in unsuccessful engaging of children in physical activities as early as pre-school age and also prepubescent ages. This may subsequently lead to a spiral of forming negative attitudes towards an active lifestyle and may be accompanied by a negative trend in weight status and physical fitness outcomes. Objective: The aim of the study was to identify and analyze differences in physical fitness and somatic parameters of primary school-aged children according to level of their gross motor coordination. Methods: A sample of 436 children aged 7 to 10 years, of which were 222 girls and 214 boys, performed physical fitness tests - Eurofit test battery. The level of motor coordination was assessed using the test battery Körperkoordination-Test-für-Kinder (KTK). The anthropometric data (body mass, body height, sum of five skinfolds) were measured. The one-way ANOVA was used to assess differences in physical fitness test items and anthropometry parameters between children with normal motor quotient $(\mathrm{MQ} \geq 86)$ and decreased levels of gross motor coordination (MQ $\leq 85)$. Results: Research findings indicate a strongly negative trend in physical development of children with motor deficits (MQ $\leq 85)$. The results of ANOVA revealed significantly less favourable level of most of the assessed physical fitness parameters in children with decreased level of motor coordination. Conclusions: The findings suggest that physical fitness outcomes of primary school-aged children are associated with a lower level of motor coordination. Motor coordination probably plays an important role in preventing, or moderating the so-called negative trajectory leading to childhood overweight or obesity.
\end{abstract}

Keywords: psychomotor competence, primary education, childhood, KTK test

\section{Introduction}

Promoting health-enhancing physical activity, physical fitness, and healthy weight status in children and youth is an ambitious and global task. However, it is still unclear how the development of health-related variables may impact each other to promote either positive or negative trajectories (Robinson et al., 2015).

Stodden et al. (2008) present a conceptual model proposed synergistic relationships among physical activity, motor competence, physical fitness, and obesity. Authors hypothesize that a low level of motor coordination results in limited opportunities for engagement in physical activities, poor health-related fitness and overall low level of motor skill competence leading to increased weight and obesity. A low level

\footnotetext{
* Address for correspondence: Ingrid Ružbarská, Department of Pre-School and Elementary Pedagogy and Psychology, Faculty of Education, University of Presov in Presov, 17. novembra 15, 08001 Presov, Slovakia. E-mail: ingrid.ruzbarska@unipo.sk
}

of motor competence may lead to disengagement in games, physical and sports activities in middle and later childhood. Consequently, this results in a negative spiral of disengagement characterized by adopting negative attitudes towards pursuing a physically active lifestyle later in life.

Wrotniak, Epstein, Dorn, Jones, and Kondilis (2006) stated that coordinated movements require biomechanical and neuromuscular systems that provide activation, timing, and sequencing of muscle activity. Children with greater motor proficiency may have more opportunities to participate in more varied physical activities, as they are better at activating and sequencing movement patterns. A higher level of gross motor coordination may result in less energy expenditure, better performance in physical fitness tests and lower levels of fatigue. In addition, it may lead to greater amounts and intensity of physical activity.

According to Marshal and Bouffard (1994) and Williams et al. (2008) children with lower motor competence, on the average, may have less opportunity 
to interact in physical activities. Inadequate motor performance may lead overweight or obese children to withdraw from participation in physical activity. Consequently, a potential reversed cycle may develop.

Fransen et al. (2012) reported that children with high motor competence scored better on physical fitness tests and participated in sports more often. Low motor competent children might be at risk of being less physically fit throughout their life. Furthermore, since low motor competent children participate less in sports, they have fewer opportunities of developing motor abilities and physical fitness and this may prevent them from catching up with their peers with average or above standard motor competence.

The level of motor coordination appears to be one of the main factors contributing to an active lifestyle. Research results highlight the need to target overweight and obese children for an early screening of motor coordination and related intervention. An increased focus on learning of motor skills, and motor development aimed at lifelong physical activity is considered to be crucial during preschool and primary school age, when children are at an optimal developmental period in terms of neurological and motor development (D’Hondt et al., 2013).

Graf et al. (2005) state that preventive intervention in primary schools offers a potentially effective tool to improve motor competence in childhood and to break through the "vicious circle": physical inactivity - motor deficit - increasing physical inactivity accompanied by weight gain.

In addition, evidence from numerous research studies indicates an inverse association between gross motor coordination and weight status in childhood (D’Hondt, Bourdeaudhuij, \& Lenoir, 2009; Hardy, Reinten-Reynolds, Espinel, Zask, \& Okely, 2012; Lubans, Morgan, Cliff, Barnett, \& Okely, 2010; Okely, Booth, \& Chey, 2004; Tsiros, Coates, Howe, Grimshaw, \& Buckley, 2011). Overweight and especially obese children are less competent in motor tasks requiring support, transmission of body mass compared with normal-weight peers (Graf et al., 2004; Lopes, Stodden, Bianchi, Maia, \& Rodrigues, 2012).

Gross motor coordination and the level of motor competence are significant predictors of physical activity. Their low levels may indirectly contribute to the development of overweight and obesity in childhood. What remains insufficiently explained is the relationship between physical fitness and gross motor coordination of children (Williams et al., 2008; Wrotniak et al., 2006).

Motor coordination may be considered both a starting point and a consequence of weight status in childhood. This reciprocal relation is probably influenced by physical activity, physical fitness, leading to a variety of individual developmental trajectories (Rodrigues, Leitão, \& Lopes, 2013). However, mechanisms of these relations and effects are still incompletely understood (D’Hondt et al., 2014; Lopes et al., 2012).

There is a need for more research studies focusing on the relationship between motor coordination and aspects health related fitness such as cardiorespiratory fitness, muscular strength, muscular endurance, and flexibility in children. The reason is that an explanation of the relations between these constructs is multifaceted (Robinson et al., 2015).

Thus, this paper is set out to determine association between the gross motor coordination and primary school-aged child physical fitness level and their somatic parameters.

\section{Methods}

\section{Participants}

The study involved a cross-sectional investigation of all pupils from the first to the fourth grades from 5 primary schools in the region of the East Slovakia. The children's parents, their class teachers and management representatives of primary schools were informed of the objectives of the research. The students involved in the system of sport training $(n=19)$ were excluded from the research sample. The research sample included only the individuals without health limitations who to full extent participated in school physical education twice a week. A total of 447 children, whose parents provided informed consent, participated in the study from the potential target group of 526 (84.98\% response rate). Their participation was voluntary. However, a total of 436 children (boys: $n=214$; girls: $n=222$ ) between 7 and 10 years of age (mean age 8.52 \pm 1.21 years) completed all test items, and their data were included in the subsequent statistical analysis. Assessments of anthropometry and gross motor coordination took place in the gymnasium of the school during physical education classes. The Ethical Committee of the Faculty of Sports, University of Presov in Presov, Slovakia (23/04/2015) approved the study.

\footnotetext{
Anthropometry

Body height $(\mathrm{BH})$ in $\mathrm{cm}$ was measured using portable stadiometer (Harpenden, Holtain, Crymych, United Kingdom) and body weight (BW) in kg using a digital scale (Omron HN-286, Omron, Kyoto, Japan). Values were recorded to the nearest $0.1 \mathrm{~cm}$ and $0.5 \mathrm{~kg}$, respectively. Body mass index (BMI) was then calculated, making use of these data $[\mathrm{BMI}=$ weight $(\mathrm{kg}) /$ height $\left(\mathrm{m}^{2}\right)$ ]. BMI was assessed according to international
} 
cut off points for body mass index for overweight and obesity by sex between 2 and 18 years (Cole, Belizzi, Flegal, \& Dietz, 2000). Five skinfolds (triceps, biceps, subscapular, supraspinal, medial calf) (SUM 5SFs) were measured on the ride side of the body to the nearest $0.1 \mathrm{~mm}$ following the protocol described by Adam, Klissouras, Ravazollo, Renson, and Tuxworth (1988). A Holtain calliper was used. Additionally, the sum of the measured skinfolds was calculated.

\section{Testing of physical fitness}

To assess the physical fitness of participants, Eurofit test system was applied (Adam et al., 1988). Children performed test items in the following order: sit-andreach (SR) - joint flexibility of the trunk; standing broad jump (JUMP) - explosive power of lower limbs; hand dynamometry (HD) - static strength of dominant hand; sit-ups in 30 seconds (SUs) - dynamic, endurance strength of abdominal and thigh muscles; bent arm hang (BAH) - static, endurance strength of upper limb muscles; shuttle run $10 \times 5$ m (SRUN) - running speed with direction changes; endurance shuttle run (ERUN) - running endurance ability.

\section{Testing of motor coordination}

Motor coordination was evaluated with the KiphardSchilling body coordination test, KörperkoordinationTest-für-Kinder (KTK) (Kiphard \& Schilling, 1974). The KTK measures gross motor coordination in typically and atypically developing children, aged 5-14 years. The test battery includes the following items:

1. Backward balance: The child walks backward on 3 balance beams $3 \mathrm{~m}$ in length, of different widths: $6 \mathrm{~cm}, 4.5 \mathrm{~cm}$, and $3 \mathrm{~cm}$. The test item score is the number of steps during backward gait.

2. Hopping obstacles: The child is instructed to hop on one foot at a time over a stack of foam squares $(50 \times 20 \times 5 \mathrm{~cm})$. After a successful hop with each foot, the height is increased by adding another square. The test item score is the number of jumps on one leg at different height.

3. Laterally jumping: The child makes consecutive jumps from side to side over a small beam as fast as possible for 15 seconds. The test score is the total number of lateral jumps performed in two consecutive attempts.

4. Sideways moving: The child begins by standing with both feet on one platform $(25 \times 25 \times 1.5 \mathrm{~cm}$, supported on $3.7 \mathrm{~cm}$ high anti-slip mats). Places the second platform alongside the first and steps on to it. Then the first platform is placed alongside the second and the child steps on to it. This sequence continues for 20 seconds. A subject has 20 second to perform and every movement of the plate is one point and step on to the other plate is one point. The points are the result from this test. The values of two valid attempts are counted.

Each performance item was scored relative to gender and age-specific reference values for the population upon which the test battery was established. The sum of the standardized scores for the examined items provides a total motor quotient (MQ). The motor quotient (MQ) adjusted for age and gender allows for an assessment of gross motor coordination in the following categories: incomplete (MQ < 56), severe motor disorder of gross motor coordination (MQ 56-70), moderate motor disorder of gross motor coordination (MQ 71-85), normal gross motor coordination (MQ 86-115), good gross motor coordination (MQ 116-130) and high gross motor coordination (MQ 131-145).

Test-retest reliability coefficient for the raw score on the total battery is .97 . Coefficients for individual test items range from .80 to .96 (Kiphard \& Schilling, 1974). The percentage of total variance in motor coordination explained by the all test items varied from $81 \%$ at the age of six and to $98 \%$ at 9 years (Kiphard \& Schilling, 1974). All assessments were conducted by trained individuals.

\section{Statistical analysis}

The normality test by Shapiro Wilk was used to verify normal data distribution. The significance level established was $5 \%(p<.05)$. For description of a level of examined physical and somatic parameters mean and standard deviation were used.

One-way ANOVA was used to determine differences in physical fitness items and somatic parameters (dependent variables) according to the distribution of motor quotient for both girls and boys (gender - categorical variable). The research group was divided into a subgroup of children with motor quotient on the level of MQ $\geq 86$ representing normal, good, and high level of gross motor coordination and into a subgroup of children with the identified motor quotient of $\mathrm{MQ} \leq 85$ defining decreased level of motor coordination, or even some possible motor deficits. Such research task was formulated on the basis of hypothesis according to which physical fitness of children with decreased gross motor coordination is lower contrary to population with standard level of motor coordination.

From the perspectives of practical significance in the examination of differences between compared groups, we applied a parameter of effect size (Cohen's d). Assessment of size of the individual coefficient stemmed from limit values recommended by Cohen (1988, 1992). 
Research data were processed by means of the program IBM SPSS Statistics (Version 20.0; IBM, Armonk, NY, USA).

\section{Results}

Of the entire sample of 436 children, $78.9 \%(n=344)$ of children showed normal or high levels of motor coordination and $21.1 \%(n=92)$ of children showed moderate, or severe motor disorder. Of the sample of 222 girls, $74.3 \%$ of girls $(n=165)$ showed normal or high levels of motor coordination and $25.7 \%$ of girls $(n=57)$ showed moderate to severe motor disorder. Moderate to severe motor disorders were found in $16.4 \%$ ( 35 boys) of the entire sample. In total, $83.6 \%$ of boys $(n=179)$ showed a normal, good or high level of motor coordination. Total of four cases $(0.92 \%)$ showed motor quotient below the level of 70 which signals severe disorder of gross motor coordination.

The anthropometric data for the whole research group are shown in Table 1. However, boys and girls with lower levels of gross motor coordination showed significantly higher level of body weight, sum of skinfolds, and BMI as indicated by practical significance with rather medium or large effect size. Research findings indicate strongly negative state of physical development of children with low motor coordination $(\mathrm{MQ} \leq 85)$.

As shown in Figure 1, of children with normal or higher level of gross motor coordination (MQ $\geq 86$ ) ( $n=344), 301(87.5 \%)$ were found to be normal-weight and only $12.5 \%$ (43) of children with overweight or obesity. In the sample of children with $\mathrm{MQ} \leq 85(n=92)$ $50 \%$ (46) were normal-weight and the same percentage of children were overweight or obese.

Of the entire sample of girls with normal or higher level of gross motor coordination (MQ $\geq 86)(n=165)$, 24 were overweight or obese. On the other hand, in the group of girls with motor quotient below normal values $(\mathrm{MQ} \leq 85)(n=57)$ such ratio is fundamentally different. More than half of girls were overweight or obese. Of 179 boys with normal or higher level of motor (MQ $\geq 86$ ), 10.6\% (19) were overweight or obese. Of the sample of boys with lowered level of motor quotient (MQ $\leq 85$ ), almost half of the group were overweight or obese. These findings point to the higher prevalence of overweight and obesity in children with lower level of gross motor coordination.

ANOVA revealed statistically significant differences between participants (girls and boys) with motor quotient under 85 and their counterparts with high level of motor quotient in several physical fitness parameters (Table 2). Primary school-aged children with motor

Table 1

Comparison of anthropometric indicators (presented as $M \pm S D$ ) in the group of girls and boys aged 7 to 10 years $(N=436)$ from the point of view of $M Q K T K$

\begin{tabular}{lccccc}
\hline & MQ $\geq 86$ & MQ $\leq 85$ & $F$ & $p$ & Cohen's $d$ \\
\hline Body weight $(\mathrm{kg})$ & & & & \\
$\quad$ Girls & $29.53 \pm 7.67$ & $32.56 \pm 9.38$ & 5.89 & $\mathbf{. 0 1 6}$ & 0.37 \\
Boys & $29.71 \pm 7.29$ & $34.86 \pm 11.77$ & 11.61 & $\mathbf{. 0 0 1}$ & 0.63 \\
Girls and boys & $29.62 \pm 7.46$ & $33.44 \pm 10.35$ & 15.87 & $<.001$ & 0.47 \\
Body height $(\mathrm{cm})$ & & & & \\
Girls & $133.67 \pm 9.63$ & $132.01 \pm 10.01$ & 1.24 & .267 & 0.17 \\
Boys & $134.26 \pm 9.82$ & $133.76 \pm 10.25$ & 0.08 & .781 & 0.05 \\
Girls and boys & $133.98 \pm 9.70$ & $132.67 \pm 10.08$ & 1.29 & .256 & 0.13 \\
SUM 5SFs (mm) & & & & & \\
Girls & $43.99 \pm 9.57$ & $48.12 \pm 11.68$ & 7.03 & $\mathbf{. 0 0 9}$ & 0.41 \\
Boys & $40.51 \pm 9.45$ & $46.03 \pm 16.24$ & 7.60 & $\mathbf{. 0 0 6}$ & 0.51 \\
Girls and boys & $42.18 \pm 9.65$ & $47.33 \pm 13.55$ & 17.14 & $\mathbf{. 0 0 1}$ & 0.49 \\
Body mass index $\left(\mathrm{kg} \cdot \mathrm{m}^{-2}\right)$ & & & & \\
Girls & $16.32 \pm 2.60$ & $18.33 \pm 3.05$ & 22.95 & $\mathbf{. 0 0 1}$ & 0.74 \\
Boys & $16.27 \pm 2.31$ & $18.98 \pm 4.18$ & 29.50 & $\mathbf{. 0 0 1}$ & 1.00 \\
Girls and boys & $16.30 \pm 2.45$ & $18.58 \pm 3.52$ & 51.40 & $\mathbf{. 0 0 1}$ & 0.84 \\
\hline
\end{tabular}

Note. $\mathrm{MQ}=$ motor quotient; SUM 5SFs $=$ sum of five skinfolds. Girls with MQ $\geq 86: n=165$; girls with MQ $\leq 85$ : $n=57$; boys with MQ $\geq 86: n=179$; boys with MQ $\leq 85: n=35$; girls and boys with MQ $\geq 86: n=344$; girls and boys with MQ $\leq 85: n=92$. Bold face indicates $p$ values smaller than .05 . 
quotient under 85 showed significantly lower scores than their counterparts with normal motor quotation level coordination in all examined physical fitness items, apart from joint flexibility (SR) and static, endurance strength of muscle of upper limbs (BAH).

For boys (Table 3 ), there were statistically significant differences between samples from the perspective of different levels of motor quotient (MQ) in strength tests (JUMP, SUs) and endurance test (ERUN). However, no statistically significant difference was found between the groups in hand dynamometry (HD), bentarm hang (BAH), and running speed test (SRUN).

Girls with motor quotient under 85 showed statistically significant lower scores in tests of strength and speed (JUMP, SUs, SR) than girls with normal or high motor quotients (Table 3). Paradoxically, girls with a lower level of gross motor coordination showed a statistically significant higher level of trunk flexibility (SR) as indicated by practical significance with small effect size. No statistically significant difference was found between the groups of girls in endurance test
(ERUN), static strength test (HD), and static, endurance strength of upper limbs test (BAH).

\section{Discussion}

The study reveals that group of children with low motor coordination had an inferior fitness level compared with the group of children with normal or high motor coordination level in almost all test items. These research findings are in accordance with studies reporting reduced aerobic and anaerobic endurance, muscular strength and endurance (Faught, Hay, Cairney, \& Flouris, 2005; Schott, Alof, Hultsch, \& Meermann, 2007) and poorer levels of speed and agility (Haga, 2008a) in children with low level of motor coordination compared with their peers with normal motor coordination.

Consistent with our partial findings, Haga (2008b) has confirmed the hypothesis that children with higher levels of motor coordination show higher physical

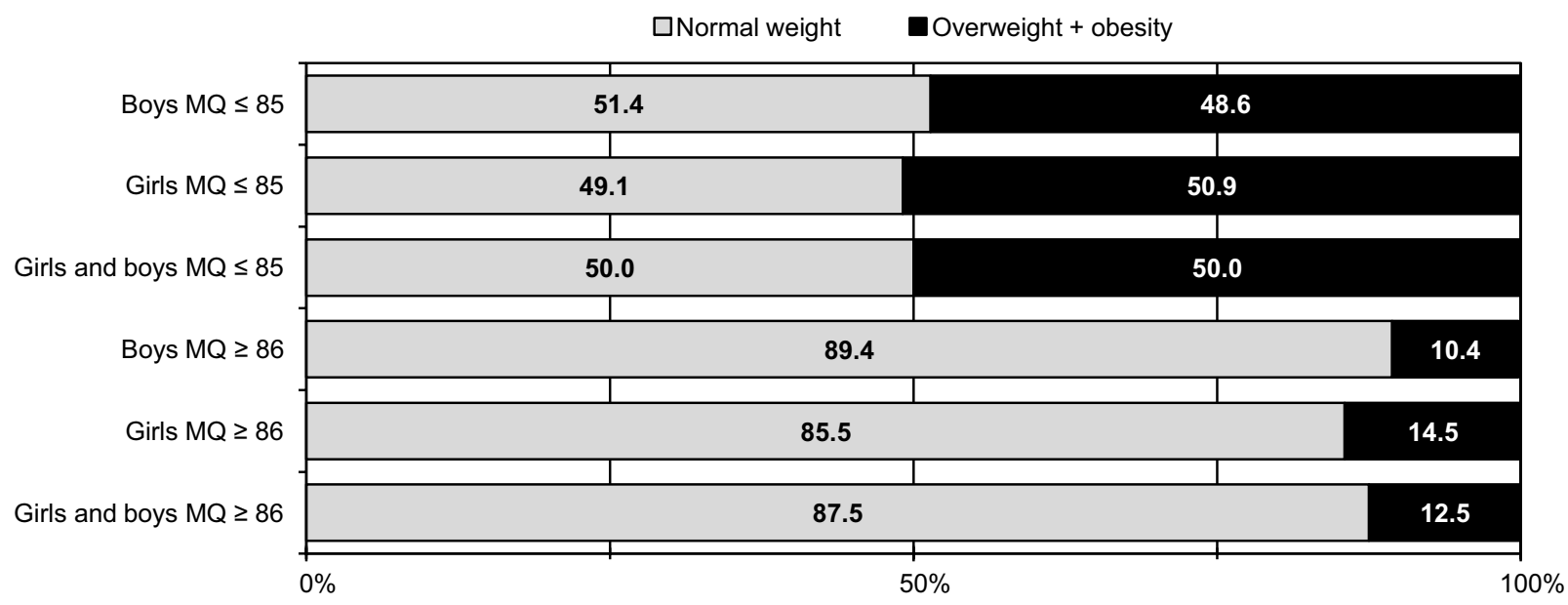

Figure 1. Distribution of body mass index in the groups divided according to motor quotient (MQ KTK).

Table 2

Comparison of physical fitness indicators (presented as $M \pm S D$ ) in the group of girls and boys aged 7 to 10 years $(N=436)$ from the point of view of $M Q K T K$

\begin{tabular}{lccrcc}
\hline & MQ $\geq 86(n=344)$ & MQ $\leq 85(n=92)$ & \multicolumn{1}{c}{$F$} & $p$ & Cohen's $d$ \\
\hline Sit-and-reach (SR; cm) & $21.25 \pm 5.83$ & $22.14 \pm 5.91$ & 1.68 & .196 & 0.15 \\
Standing broad jump (SBJ; cm) & $126.08 \pm 22.62$ & $115.26 \pm 20.36$ & 17.31 & $<.001$ & 0.49 \\
Hand dynamometry (HD; kg) & $16.85 \pm 4.67$ & $15.74 \pm 5.37$ & 3.87 & $\mathbf{. 0 4 9}$ & 0.23 \\
Sit-ups in 30 seconds (SUs; n) & $17.14 \pm 5.10$ & $14.92 \pm 5.73$ & 13.04 & $\mathbf{. 0 0 1}$ & 0.42 \\
Bent-arm hang (BAH; s) & $16.45 \pm 8.78$ & $14.06 \pm 6.09$ & 2.97 & .085 & 0.20 \\
Shuttle run 10×5 m (SRUN; s) & $24.08 \pm 2.51$ & $25.02 \pm 2.79$ & 9.83 & $\mathbf{. 0 0 2}$ & 0.37 \\
Endurance shuttle run (ERUN; n) & $22.96 \pm 9.17$ & $19.58 \pm 8.49$ & 10.17 & $\mathbf{. 0 0 2}$ & 0.37 \\
\hline
\end{tabular}

Note. $\quad \mathrm{MQ}=$ motor quotient. Bold face indicates $p$ values smaller than .05 . 
Table 3

Comparison of physical fitness indicators (presented as $M \pm S D$ ) in group of girls and boys aged 7 to 10 years $(N=436)$ from the point of view of $M Q K T K$

\begin{tabular}{|c|c|c|c|c|c|}
\hline & $\mathrm{MQ} \geq 86$ & $\mathrm{MQ} \leq 85$ & $F$ & $p$ & Cohen's $d$ \\
\hline \multicolumn{6}{|c|}{ Sit-and-reach (SR; cm) } \\
\hline Girls & $21.79 \pm 5.36$ & $23.75 \pm 5.89$ & 5.38 & .021 & 0.36 \\
\hline Boys & $20.75 \pm 6.20$ & $19.51 \pm 5.00$ & 1.24 & .266 & 0.21 \\
\hline \multicolumn{6}{|c|}{ Standing broad jump (SBJ; cm) } \\
\hline Girls & $119.90 \pm 21.76$ & $113.23 \pm 18.53$ & 4.29 & .040 & 0.32 \\
\hline Boys & $131.81 \pm 21.93$ & $118.57 \pm 22.93$ & 10.51 & .001 & 0.60 \\
\hline \multicolumn{6}{|c|}{ Hand dynamometry (HD; kg) } \\
\hline Girls & $15.05 \pm 4.18$ & $14.63 \pm 4.86$ & 1.69 & .196 & 0.20 \\
\hline Boys & $18.10 \pm 4.76$ & $17.54 \pm 5.72$ & 0.37 & .542 & 0.11 \\
\hline \multicolumn{6}{|c|}{ Sit-ups in 30 seconds (SUs; $\mathrm{n}$ ) } \\
\hline Girls & $16.28 \pm 4.73$ & $14.44 \pm 5.22$ & 6.07 & .015 & 0.38 \\
\hline Boys & $17.94 \pm 5.30$ & $15.71 \pm 6.48$ & 4.78 & .030 & 0.40 \\
\hline \multicolumn{6}{|c|}{ Bent-arm hang (BAH; s) } \\
\hline Girls & $14.06 \pm 7.99$ & $12.68 \pm 5.99$ & 0.79 & .376 & 0.14 \\
\hline Boys & $18.64 \pm 8.95$ & $16.32 \pm 7.99$ & 0.95 & .332 & 0.18 \\
\hline \multicolumn{6}{|c|}{ Shuttle run $10 \times 5$ m (SRUN; s) } \\
\hline Girls & $24.24 \pm 2.26$ & $25.34 \pm 2.97$ & 8.42 & .004 & 0.45 \\
\hline Boys & $23.92 \pm 2.72$ & $24.51 \pm 2.41$ & 1.40 & .239 & 0.22 \\
\hline \multicolumn{6}{|c|}{ Endurance shuttle run (ERUN; n) } \\
\hline Girls & $21.24 \pm 7.15$ & $19.35 \pm 7.78$ & 2.82 & .095 & 0.26 \\
\hline Boys & $24.54 \pm 10.47$ & $19.94 \pm 9.65$ & 5.79 & .017 & 0.44 \\
\hline
\end{tabular}

fitness levels than children with lower levels of motor coordination. The findings of Cantell, Crawford, and Doyle-Parker (2008) indicated reduced muscular endurance for 8-9 years old children with low motor coordination.

Several research studies have confirmed low levels of aerobic endurance in children diagnosed with a moderate motor disorder. Five to eight years old children with moderate motor disorders were found to have below-average or low levels of flexibility, lowerbody explosive strength, running speed with changes of direction and abdominal endurance (Haga, 2009). Similar findings result from our comparisons, excluding flexibility in the group of girls.

Williams et al. (2008) report that the level of gross motor coordination is an important factor that promotes physical activity of children since early childhood. Children with better-developed motor coordination may find it easier to be active and engage in more physical activity than those with lower level of motor competence.
Lower gross coordination is a crucial predictor underlying creation of self-perception and also self-evaluation of children's own competences in the domain of physical activity. Motor "insufficiency", accompanying negative feelings, lack of success may lead to decreased motivation to participate in or even avoid movement games and physical activities. Naturally, such a situation is determined both positively and negatively by the social context, parents, teachers and peers. Informal leisure-time physical activity performed by children at this age may very improbably transfer to the development of aerobic endurance or strength development as well as development of overall health-oriented physical fitness. On the other hand, variety and a sufficient level of motor experience of children may reflect in the adequate development of their coordination (Haga, 2009).

Hands and Larkin (2006) found that children between 5 to 8 years old with motor learning difficulties had significantly poorer performance on fitness test, such as sit and reach, sit-ups, standing broad jump, and shuttle run. Along with this, these children had a significantly higher body mass index. 
Our findings are not concurrent with the findings of Psotta, Kokštejn, Jahodová, and Frýbort (2010). The authors, by studying 404 Czech children (mean age $9.4 \pm 1$ years), found that $4.4 \%$ of these children showed lowered motor coordination or motor deficits. This incidence is two times lower than in pubertal children. The authors reported that both boys and girls who demonstrated lower motor coordination did not significantly differ in the BMI from their agematched healthy counterparts of the same sex. Our findings point to the higher prevalence of overweight and obesity, and significantly higher sum of skinfolds in children with lower levels of gross motor coordination. Naturally, such comparison is problematic due to application of various methodological approaches.

Several studies showed more limited motor skills and abilities among obese boys compared to normal weight peers, but these results were not shown in girls (Cawley \& Spiess, 2008). D'Hondt et al. (2011) reported that childhood overweight and obesity significantly contribute to lower level of motor coordination. Such impairment of motor development starts in preschool age (Logan, Scrabis-Fletcher, Modlesky, \& Getchell, 2011) and become more intensive at primary school age (Lopes et al., 2012). Inverse relations between motor competence and weight status may emerge at pre-school age. There are indications that childhood overweight or obesity as well as motor competence has been linked with rather sedentary lifestyle (Jimenez-Pavón, Kelly, \& Reilly, 2010). The level of children's motor competence is considered to be a predictor of adiposity (Rodrigues et al., 2013).

A review of 40 studies reported varying degrees of negative association between body composition, cardiorespiratory fitness, muscle strength and endurance physical activity, and poor motor competence in children (Rivilis et al., 2011).

In addition, many studies have concluded a positive relationship between motor coordination and organized sports participation in early and later childhood. Gross motor competence may be considered a key factor for engagement in organised physical activities (Graf et al., 2004). In line with these suggestions, gross motor competence may lead to increased sports participation and vice versa. Organised physical activities are beneficial for healthy motor development (Lopes et al., 2012; Malina, 2009).

Poor motor coordination and frustration from inadequacy in motor activities may lead to decreased motivation to participate in physical activity, and the child may voluntarily withdraw from physical activity. This may result in a negative interaction between reduced motor coordination, and a low level of physical activity, placing further motor development, physical fitness, and health at risk (Bouffard, Watkinson, Thompson, Dunn, \& Romanow, 1996). A deficit in motor proficiency may influence the affection-social behaviours, having a negative impact over self-esteem as well as motivation for physical activity practice (Ulrich, 2000).

As reported by Haga (2009), it is improbable to assume that children with motor problems are likely to grow out of such problems. Yet, a variety of motor deficits tend to persist into adulthood. Low motor competence has long-term unfavourable effects on other domains of personality development affecting especially socio-affective and cognitive skills.

The cross-sectional design of the analysis limits casual interpretations of our findings. What remains crucial is the 'role' of motor performance in a complex mechanism underlying the adoption of a healthy lifestyle as early as childhood.

\section{Conclusion}

Our findings suggest that motor coordination has implications for different components of physical fitness in primary school children. Children with lowered gross motor coordination performed more poorly than their peers with a normal, good or high level of gross motor coordination on almost all fitness test items. Moreover, our findings point to the higher prevalence of overweight and obesity, and significantly higher sum of skinfolds in children with a lower level of motor coordination (children with moderate, severe motor disorder of gross motor coordination or children with incomplete motor coordination).

Somewhere at the beginning is most probably physical inactivity leading to motor deficits and consequently supporting physical inactivity and sedentary lifestyle of children, which may be accompanied by excess energy intake, excess body weight, and poor physical fitness outcomes.

However, further investigation is needed to provide an improved clarification of the relationship between motor competence and physical fitness level.

Our results revealed that motor competence plays an important part in physical fitness outcomes of primary school-aged children. Children with low motor coordination are likely to have poorer physical fitness compared to children with normal and high gross motor coordination. Since various physical fitness components seems to be linked to different health outcomes, these implications should be matters of concern for health status in children with a low level of gross motor coordination.

Furthermore, gross motor coordination and physical fitness should not be seen as separate constructs. 
Conversely, they should be seen as simultaneous goals to develop functional capabilities in children that allow them to participate successfully in many types of health-enhancing physical activities.

\section{Acknowledgment}

The paper was supported by the scientific project No. 1/0625/16, "Effectiveness of physical activities on the development of motor abilities in intact and integrated children with behavioral disorders", which is funded by the Scientific Grant Agency of the Ministry of Education, Science, Research and Sports of the Slovak Republic and Slovak Academy of Sciences.

\section{Conflict of interest}

There were no conflicts of interest.

\section{References}

Adam, C. V., Klissouras, M., Ravazollo, R., Renson, W., \& Tuxworth, W. (1988). Eurofit. Handbook for the European test of physical fitness. Rome, Italy: Council of Europe, Committee for Development of Sport.

Bouffard, M., Watkinson, E. J., Thompson, L. P., Dunn, J. L. C., \& Romanow, S. K. E. (1996). A test of the activity deficit hypothesis with children with movement difficulties. Adapted Physical Activity Quarterly, 13, 61-73.

Cantell, M. H., Crawford, S. G., \& Doyle-Parker, P. K. (2008). Physical fitness and health indices in children, adolescents and adults with high or low motor competence. Human Movement Science, 27, 344-362.

Cawley, J., \& Spiess, C. K. (2008). Obesity and skill attainment in early childhood. Economics \& Human Biology, 6, 388-397.

Cohen, J. (1988). Statistical power analysis for the behavioural science (2nd ed.). Hillsdale, NJ: Erlbaum.

Cohen, J. (1992). Quantitative methods in psychology. Psychological Bulletin, 112, 155-159.

Cole, T. J., Belizzi, M. C., Flegal, K. M., \& Dietz, W. H. (2000). Establishing a standard definition for overweight and obesity worldwide: International survey. BMJ, 320, 1240-1243.

D’Hondt, E., De Bourdeaudhuij, I., \& Lenoir, M. (2009). Relationship between motor skills and body mass index in 5 to 10 years old children. Adapted Physical Activity Quarterly, 26, 21-37.

D'Hondt, E., Deforche, B., Gentier, I., De Bourdeaudhuij, I., Vaeyens, R., Philippaerts, R., \& Lenoir, M. (2013). A longitudinal analysis of gross motor coordination in overweight and obese children versus normal-weight peers. International Journal of Obesity, 37, 61-67.

D’Hondt, E., Deforche, B., Gentier, I., Verstuyf, J., Vaeyens, R., Bourdeaudhuij, I. D., ... Lenoir, M. (2014).
A longitudinal study of gross motor coordination and weight status in children. Obesity, 22, 1505-1511.

D’Hondt, E., Deforche, B., Vaeyens, R., Vandorpe, B., Vandendriessche, J., Pion, J., ... Lenoir, M. (2011). Gross motor coordination in relation to weight status and age in 5- to 12-year-old boys and girls: A cross-sectional study. International Journal of Pediatric Obesity, 6, e556-e564.

Faught, B. E., Hay, J. A., Cairney, J., \& Flouris, A. (2005). Increased risk for coronary vascular disease in children with developmental coordination disorder. Journal of Adolescent Health, 37, 376-380.

Fransen, J., Pion, J., Vandendriessche, J., Vandorpe, B., Vaeyens, R., Lenoir, R., \& Philippaerts, R. M. (2012). Differences in physical fitness and gross motor coordination in boys aged 6-12 years specializing in one versus sampling more than one sport. Journal of Sports Sciences, 30, 379-386.

Graf, C., Koch, B., Falkowski, G., Jouck, S., Christ, H., Stauenmaier, K., ... Predel, H. G. (2005). Effects of a school-based intervention on BMI and motor abilities in childhood. Journal of Sports Science \& Medicine, 4, 291-299.

Graf, C., Koch, B., Kretschmann-Kandel, E., Falkowski, G., Christ, H., Coburger, S., ... Dordel, S. (2004). Correlation between BMI, leisure habits and motor abilities in childhood (CHILT-project). International Journal of Obesity, 28, 22-26.

Haga, M. (2008a). Physical fitness in children with movement difficulties. Physiotherapy, 94, 253-259.

Haga, M. (2008b). The relationship between physical fitness and motor competence in children. Child: Care, Health and Development, 34, 329-334.

Haga, M. (2009). Physical fitness in children with high motor competence is different from that in children with low motor competence. Physical Therapy, 89, 1089-1097.

Hands, B. P., \& Larkin, D. (2006). Physical fitness differences in children with and without motor learning difficulties. European Journal of Special Needs Education, 21, 447-456.

Hardy, L. L., Reinten-Reynolds, T., Espinel, P., Zask, A., \& Okely, A. D. (2012). Prevalence and correlates of low fundamental movement skill competency in children. Pediatrics, 130, e390-e398.

Jimenez-Pavón, D., Kelly, J., \& Reilly, J. J. (2010). Associations between objectively measured habitual physical activity and adiposity in children and adolescents: Systematic review. International Journal of Pediatric Obesity, 5, 3-18.

Kiphard, E. J., \& Schilling, F. (1974). KörperkoordinationTest-für-Kinder (Manual). Weinheim, Germany: Beltz Test $\mathrm{GmbH}$.

Logan, S. W., Scrabis-Fletcher, K., Modlesky, C., \& Getchell, N. (2011). The relationship between motor skill proficiency and body mass index in preschool children. Research Quarterly for Exercise and Sport, 82, 442-448.

Lopes, V. P., Stodden, D. F., Bianchi, M. M., Maia, J. A., \& Rodrigues, L. P. (2012). Correlation between BMI and motor coordination in children. Journal of Science and Medicine in Sport, 15, 38-43.

Lubans, D. R., Morgan, P. J., Cliff, D. P., Barnett, L. M., \& Okely, A. D. (2010). Fundamental movement skills in children and adolescents: Review of associated health benefits. Sports Medicine, 40, 1019-1035. 
Malina, R. M. (2009). Children and adolescents in the sport as a context for youth culture: The overwhelming majority to the select few. Journal of Exercise Science \& Fitness, 7(2), S1-S10.

Marshall, J. D., \& Bouffard, M. (1994). Obesity and movement competency in children. Adapted Physical Activity Quarterly, 11, 297-305.

Okely, A. D., Booth, M. L., \& Chey, T. (2004). Relationship between body composition and fundamental movement skills among children and adolescents. Research Quarterly for Exercise and Sport, 75, 238-247.

Psotta, R., Kokštejn, J., Jahodová, G., \& Frýbort, P. (2010). Je nízká motorická kompetence rizikovým faktorem nadváhy a obesity u dětí mladšího školního věku? [Is the impaired motor proficiency the risk factor of overweight and obesity in young school-age children?]. Česká kinantropologie, 14(2), 96-106.

Rivilis, I., Hay, J., Cairney, J., Klentrou, P., Liu, J., \& Faught, B. E. (2011). Physical activity and fitness in children with developmental coordination disorder: A systematic review. Research in Developmental Disabilities, 32, 894-910.

Robinson, L. E., Stodden, D. F., Barnett, L. M., Lopes, V. P., Logan, S. W., Rodrigues, L. P., \& D'Hondt, E. (2015). Motor competence and its effect on positive developmental trajectories of health. Sports Medicine, 45, 1273-1284.
Rodrigues, L. P., Leitão, R., \& Lopes, V. P. (2013). Physical fitness predicts adiposity longitudinal changes over childhood and adolescence. Journal of Science and Medicine in Sport, 16, 118-123.

Schott, N., Alof, V., Hultsch, D., \& Meermann, D. (2007). Physical fitness in children with developmental coordination disorder. Research Quarterly for Exercise and Sport, 78, 438-450.

Stodden, D. F., Goodway, J. D., Langendorfer, S. J., Roberton, M. A., Rudisill, M. E., Garcia, C., \& Garcia, L. E. (2008). A developmental perspective on the role of motor skill competence in physical activity: An emergent relationship. Quest, 60, 290-306.

Tsiros, M. D., Coates, A. M., Howe, P. R. C., Grimshaw, P. N., \& Buckley, J. D. (2011). Obesity: The new childhood disability? Obesity Reviews, 12, 26-36.

Ulrich, D. A. (2000). Test of gross motor development (2nd ed.). Austin, TX: Pro-ed.

Williams, H. G., Pfeiffer, K. A., O’Neill, J. R., Dowda, M., McIver, K. L., Brown, W. H., \& Pate, R. R. (2008). Motor skill performance and physical activity in preschool children. Obesity, 16, 1421-1426.

Wrotniak, B. H., Epstein, L. H., Dorn, J. M., Jones, K. E., \& Kondilis, V. A. (2006). The relationship between motor proficiency and physical activity in children. Pediatrics, $118,1758-1765$. 